\title{
Explosive Resistance Training Using Elastic Bands in Young Female Team Handball Players
}

(ㄷ)(1)(8) $\Theta$

\section{Authors}

Vidar Andersen', Marius Steiro Fimland ${ }^{2,3}$, Kristoffer Toldnes Cumming ${ }^{4}$, Øyvind Vraalsen', Atle Hole Saeterbakken ${ }^{1}$

\section{Affiliations}

1 Faculty of Education, Arts and Sports, Western Norway University of Applied Sciences, Norway

2 Department of Neuromedicine and Movement Science, Faculty of Medicine and Health Sciences, Norwegian University of Science and Technology, Trondheim, Norway.

3 Department of Physical Medicine and Rehabilitation, St. Olavs Hospital, Trondheim University Hospital, Trondheim, Norway

4 Department of Physical Performance, Norwegian School of Sport Sciences, Oslo, Norway

Key words variable resistance, strength training, handball performance

received 27.06 .2018

revised 23.08.2018

accepted 05.09.2018

\section{Bibliography}

DOI https://doi.org/10.1055/a-0755-7398

Sports Medicine International Open 2018; 2: E171-E178

(C) Georg Thieme Verlag KG Stuttgart · New York

ISSN 2367-1890

\section{Correspondence}

Mr. Vidar Andersen

Faculty of Teacher Education and Sport

Sogn og Fjordane University College

Pb 133, 6851 Sogndal

Norway

Tel.: +47/676/76 164, Fax: +47/576/76333

Vidar.andersen@hvl.no

\begin{abstract}
The aim of the study was to examine the effects of full-body elastic resistance band training in young female team handball players. 12 players $(16.5 \pm 0.7$ years, $166 \pm 5.0 \mathrm{~cm}, 65.9 \pm 8.8 \mathrm{~kg}$ ) completed an 11 -week control period followed by a 9 -week elastic resistance band training period. The training program, consisting of 6 exercises, was incorporated into the teams' regular handball training sessions 3 times per week. Each exercise was performed with 3 sets of $6-10$ explosive repetitions (5-9 on the Borg CR10 Scale ${ }^{\circledR}$ ). The maximal power output in squat and bench press, jump height, throwing velocity and repeated agility run was tested before and after the control and training periods. The elastic resistance band period had greater improvement vs. the control period for countermovement jump with or without arm swing ( $10 \%$ vs. -6 to $-2 \%$ ) and power output at lighter loads ( 10 to $12 \%$ vs. -6 to $0 \%$ ). For the 3 throwing velocity tests, there were tendencies towards increased velocity in the elastic resistance band period compared to the control period $(p=0.07-0.10)$. For the repeated agility run, there was a reduction in the mean and fastest time compared to the training period ( 2 to $3 \%$ vs. -1 to $1 \%$ ). In conclusion, a brief, elastic resistance band training program, incorporated into the regular handball training sessions, improved explosive lower-limb performance in young female handball players more than handball training alone.
\end{abstract}

\section{Introduction}

Team handball is a sport characterized by intermittent work with periods at various intensities $[4,21]$. Although most of the time in a match is at lower intensities, most of the decisive movements such as accelerations, sprinting, tackles, jumping and throwing demands a high level of explosiveness and strength $[3,5,20]$. Independent of the player position, a decline in performance are observed in matches [26].
The effects of resistance training on physical performance among team handball players have been investigated in several studies [12-14, 17-19,23]. 4 of these studies used free weights in the training program and reported that resistance training led to improved power output, strength, throwing velocity, jump height and sprint velocity among male, adult handball players [12-14, 17]. However, using free weights as a part of the training schedule has some disadvantages. It often requires access to fitness center fa- 
cilities, which can be expensive and imposes extra training sessions in addition to the specific handball sessions. Elastic resistance bands have been suggested as a good alternative to traditional strength training equipment [24]. Elastic resistance bands are inexpensive, easy to use, portable, and easier to implement in regular handball training sessions than conventional resistance training equipment.

2 studies examined the effect of elastic resistance band training on physical performance among handball players $[18,19]$. Both studies performed a 6 -week intervention on young, female, amateur team handball players conducting 2 exercises on the shoulder rotators, with 3 sets of 10 repetitions in each exercise. Comparing the intervention with the control group, they reported increased power output in the shoulder muscles [19] as well as increased isokinetic strength in external rotation at slow concentric and high eccentric velocities [18]. However, there were no between-group differences in throwing velocity.

As the effect of whole-body elastic resistance band training on physical performance has not been studied in team handball players, we implemented a brief, explosive program into the regular handball sessions after a control period with regular training. We hypothesized that the elastic resistance band program would increase performance in repeated agility run, throwing velocity, jumping ability and power output in both the lower and upper body more than team handball training alone.

\section{Materials \& Methods}

\section{Study overview}

The participants completed an 11-week control period before they started a 9-week elastic resistance band program. Repeated agility run, throwing velocity, jumping performance, and power in the squat and bench press were tested before the control period ( pre $_{\text {con }}$ ), between the control and the training period (pre train $_{\text {) }}$ and after the training period ( post $_{\text {train }}$ ).

\section{Participants}

14 players from a female junior handball team participated. They had $7.8 \pm 2.6$ years of handball experience. 6 of the players had no previous experience with resistance training; the rest had some experience, but none performed weekly resistance training.

During the study period, the participants were instructed to adhere to the teams ` training schedule and not change their private training routine. Before the pre $_{\text {con }}$ tests, the participants received oral and written information concerning the procedures and possible risks associated with the study. Further, they provided written informed consent before being enrolled in the study. For participants under the age of 18 , written consent was also obtained from the parents. The study conformed to the latest revision of the Declaration of Helsinki and the ethical guidelines at the Western Norway University of Applied Sciences and was approved by the Norwegian Centre for Research Data before the start of the study. The study also meets the ethical standards of the International Journal of Sports Medicine [11].

During the study period, 2 of the 14 subjects withdrew from the study, one due to injury and one quit the team. The remaining $12 \mathrm{sub}-$ jects were $16.5 \pm 0.7$ years old with a height of $166 \pm 5.0 \mathrm{~cm}$. Body weight at the start was $65.9 \pm 8.8 \mathrm{~kg}$ and at the end $65.7 \pm 9.1 \mathrm{~kg}$.

\section{Test procedures}

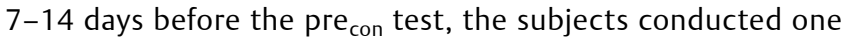
familiarization session with the repeated agility test and 2 sessions with the squat and bench press tests. Being handball players, they were quite familiar with jumping and throwing. Therefore, no familiarization sessions were conducted before these tests. Testing was performed on 2 separate days, with repeated agility and throwing velocity on day 1 , and jumping ability and power output in the squat and the bench press, in that order, on day 2 (2-3 days later). The subjects were instructed to refrain from high-intensity training in the $48 \mathrm{~h}$ prior to testing. The same test leader administered all the tests.

The warm-up procedure was standardized and identical at all 3 test points. On the first test day, the subjects performed a 15-min warm-up at progressive intensity before the repeated agility test. The warm-up consisted of jogging (forwards and backwards), fast runs with change of direction, sideways movements and sprinting. Between the repeated agility and the throwing velocity test, the subjects had 10 min of active recovery, which included a specific warm-up of the upper body to prepare for the throwing velocity test. On the second test day, the subjects started with a 10-min general warm-up consisting of jogging followed by a specific warmup consisting of 8-10 countermovement jumps. Between the jump and the power tests, the subjects were given an active recovery of $5 \mathrm{~min}$. Next, they completed 2 sets of 8 non-fatiguing repetitions in each exercise of the power tests using 20 (squat) or $15 \mathrm{~kg}$ (bench press).

\section{Repeated agility run}

The course for the repeated agility run was custom-made for this study and included different handball-specific movements, such as sprinting (forwards and backwards), sideways movement and rapid changes of direction ( $\triangleright$ Fig. 1). Poles $(170 \mathrm{~cm}$ ) were used to mark the different parts of the course. The subjects were instructed to complete the course as fast as possible, but to maintain proper movement technique, simulating the handball-specific movements in the different parts of the course. The starting position was $30 \mathrm{~cm}$ behind a timing gate at the start line and stopped when the subjects passed the timing gate at the end line. To mimic the activity profile of a handball match, the course was completed 6 times with one minute active recovery between each run. The best and the mean of the 6 runs were used in the analysis.

\section{Throwing velocity tests}

Throwing velocity was evaluated in 3 different overarm throws: the penalty throw, 3-step running throw and 3-step jump throw. The penalty throw was performed from the 7-meter line and the subjects needed to have one foot in contact with the floor during the throw. Both the running and jump throws were executed from the 9-meter line. In the running throw, the subjects did a 3-step run before the throw. Also, the lead foot had to be in contact with the 9-meter line when the ball was released from the hand. In the jump throw, the subjects performed 3 steps before jumping vertically. The ball had to be released when aligned with or slightly behind the 9 -meter line.

The subjects were instructed to throw as hard as possible and aim for a velocity radar gun (Speed TracX, Gamma Sports, Pittsburgh, Pennsylvania, USA) positioned in the center of the goal, 1.5 meters behind the goal line. The ball used during testing was an IHF-approved Select handball (mass 350-370 g, circumference 
$54-56 \mathrm{~cm})$. In general, 3 attempts were allotted for each type of throw. However, if the third attempt was the best, the subject continued until the velocity of the throw decreased. One minute of rest was given between each attempt. The best attempt from each type of throw was used in the analysis.

\section{Jump tests}

Jumping ability was evaluated in 2 different jump tests: countermovement jump (CMJ) and CMJ with arm swing (CMJas) on a force platform (MuscleLab Force Plate model 2; Ergotest Technology AS, Porsgrunn, Norway). The jump height was calculated by the impulse using a software program (MuscleLab v8.13; Ergotest Technology AS, Porsgrunn, Norway). The subjects had 3 attempts for each type of jump. If the third attempt was the best, the subject continued until jump height decreased. In the CMJ, the subjects were instructed to descend rapidly to a depth of approximately $90^{\circ}$ in the knees before starting the concentric phase as fast as possible. The hands were kept on the hips throughout the jump. After completing the CMJ, the CMJas was performed in a similar fashion, but with an arm swing. One minute of rest was given between each attempt. The best attempt from the CMJ and the CMJas was used in the analysis.

\section{Power tests}

The maximal power output was tested for a range of submaximal loads during the ascending/concentric squat and bench press. A linear encoder (Ergotest Technology AS, Langesund, Norway) was attached to the bar in both exercises. The encoder recorded the position, direction, bar displacement and time. A software program calculated the mean power output and average velocity of each attempt (MuscleLab Software v8.13, Ergotest Technology AS, Langesund, Norway). 2 attempts were given at each load and the best (highest mean power) was used in the analysis. $2-3$ min of rest was given between each attempt.

The squat was performed in a Smith machine (Sportsmaster, Asker, Norway), using loads of $20,30,40,50$ and $60 \mathrm{~kg}$. The starting position was at a $90^{\circ}$ angle in the knees. The width between and the rotation of the feet was self-selected, but recorded and used in later tests. The subjects were instructed to keep their back straight and perform the lifts as quickly and explosively as possible until full extension of the hip and knees was achieved. The bar had to be in contact with the shoulders throughout the test.

The bench press was performed with free weights (bench and an Olympic bar) using loads of 15, 20, 25 and $30 \mathrm{~kg}$. In the starting position, the bar was centered on the sternum. The width of the grip was self-selected, but measured and kept identical at all tests. The subjects were instructed to lift the bar as quickly and explosively as possible until their arms were fully extended. Their bottom, shoulders and head had to be in contact with the bench throughout the lift.

\section{Intervention}

\section{Control period}

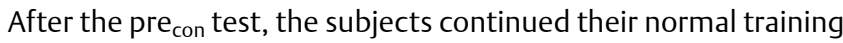
routine for 11 weeks. This routine consisted of 4 handball sessions per week, approximately one match per week and the players ` individual training.

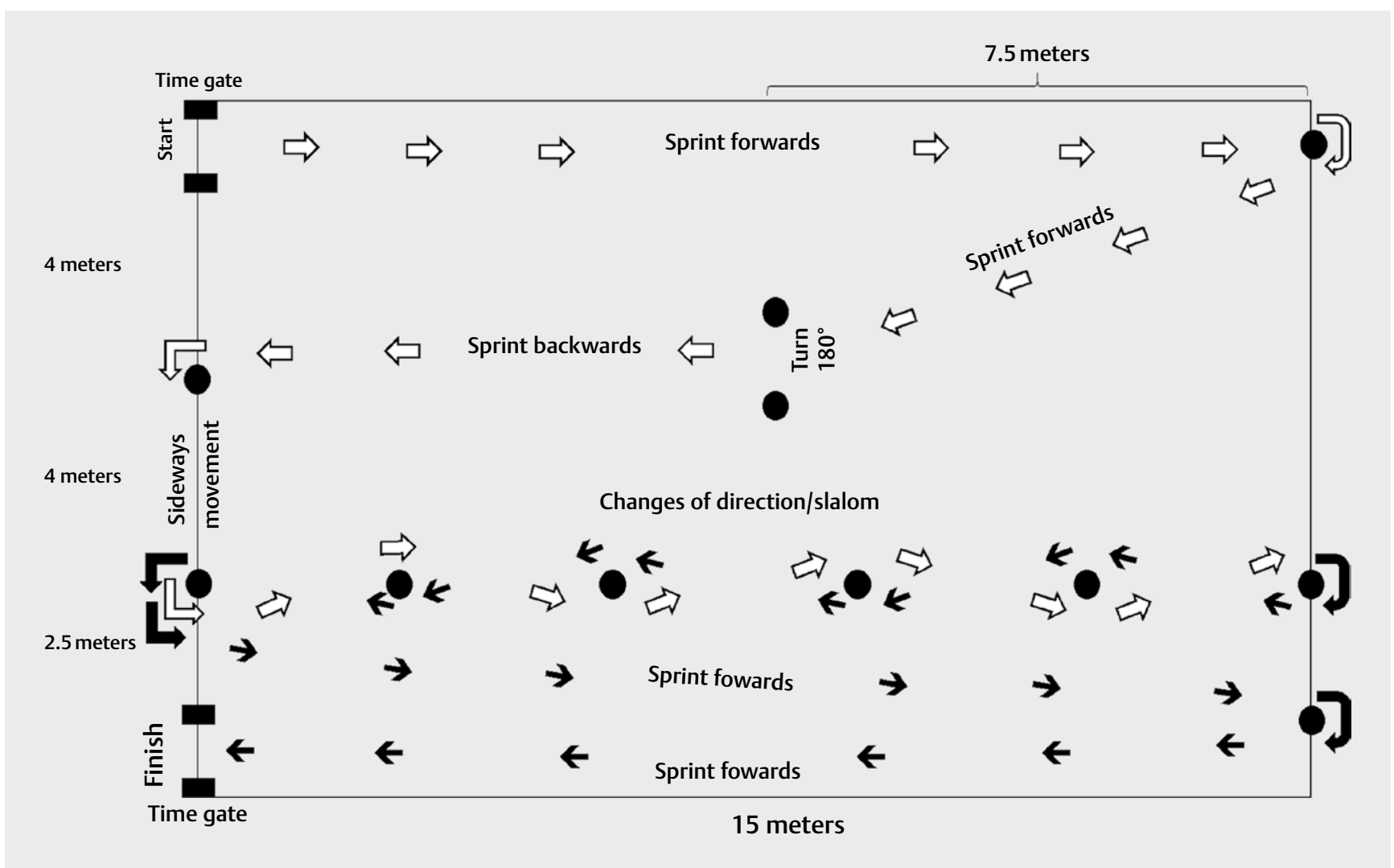

Fig. 1 Illustration of the repeated agility run course. 


\section{Training}

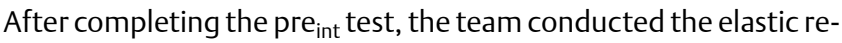
sistance band program 3 times per week for 9 weeks. The program consisted of 6 exercises ( $\boldsymbol{F}$ Fig. 2), performed with elastic bands (www.ropes.no): Bulgarian squat, unilateral handball throw, flies, row with high elbows, triceps extension and trunk rotation. 2 different bands were used, red and black. Red and black bands provided approximately 65 and 140 newtons when stretched one meter, respectively. With the exception of the triceps extension, the height of the bands (on the wall bar) was the same for all subjects in each exercise throughout the training period. The resist- ance from the bands was adjusted with the distance from the wall bars to the subject or the band with greater resistance was used. Further, the distance and type of elastic resistance band was noted for each session to ensure progression. For the triceps extension, the resistance from the elastic bands was adjusted by lowering or elevating the attachment point to the wall bars.

The program progressed from 3 sets of 10 repetitions at $5-6$ on the Borg CR10 Scale $\circledR$ (week $1-3$ ), via 3 sets of 8 repetitions at 6-7 on the Borg CR10 Scale ${ }^{\circledR}$ (week 4-6) to 3 sets of 6 repetitions at 7-8 on the Borg CR10 Scale ${ }^{\circledR}$ (week 7-9). If the subjects expressed an intensity level lower than the intended, they had to increase the

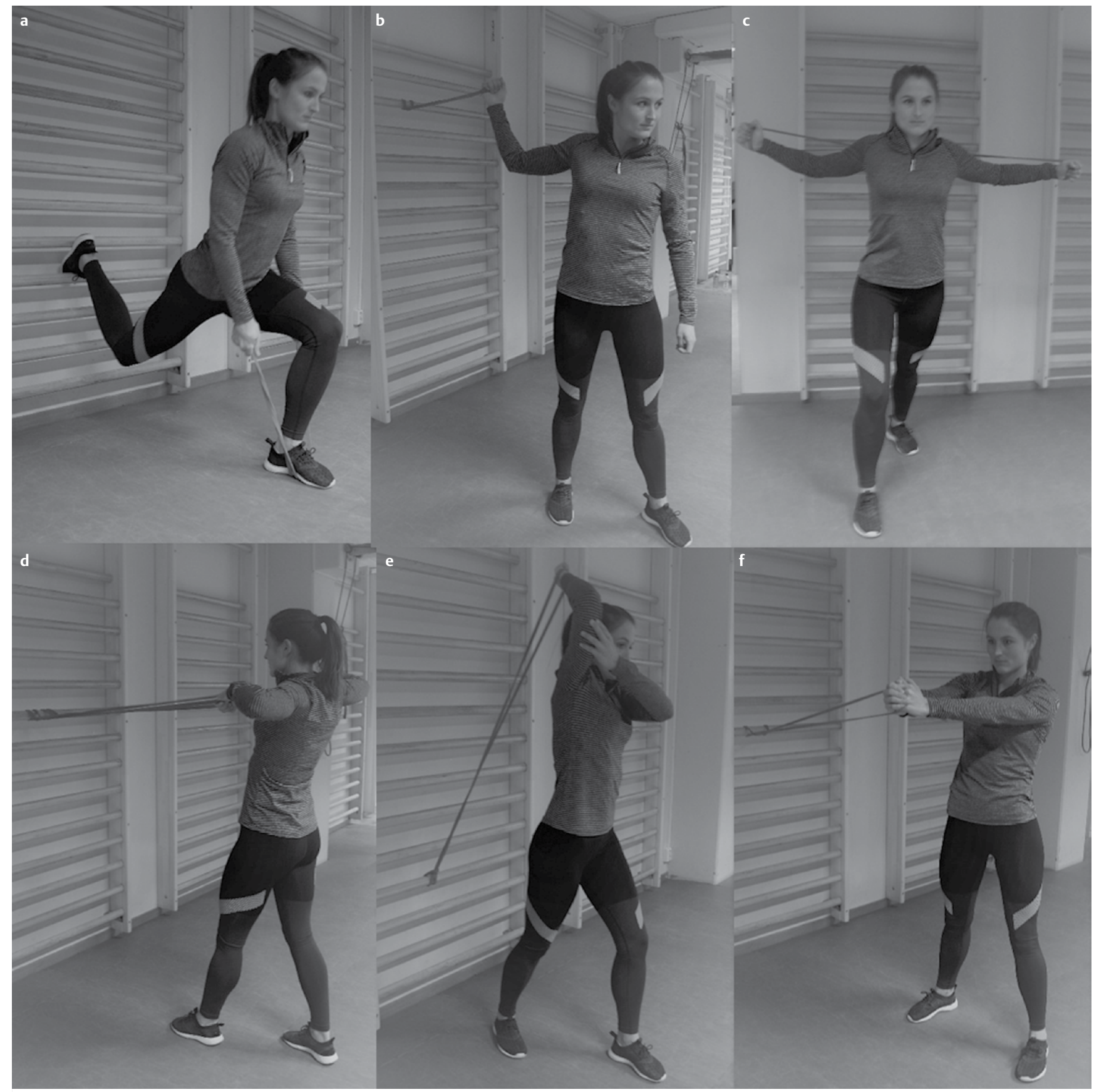

- Fig. 2 The exercises in the training program: Bulgarian squat a, unilateral handball throw $\mathbf{b}$, flies $\mathbf{c}$, row with high elbows $\mathbf{d}$, triceps extension $\mathbf{e}$ and trunk rotation $\mathbf{f}$. 


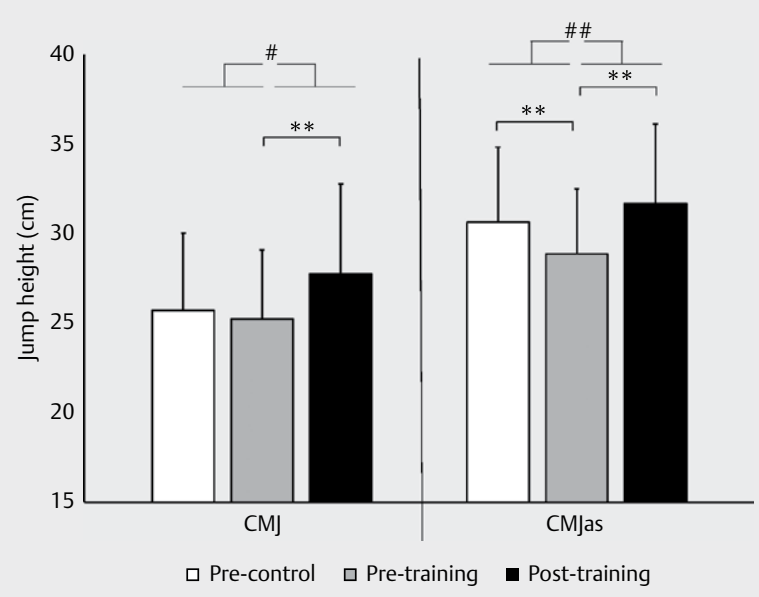

- Fig. 3 Jump height in the countermovement jump (CMJ) and CMJ with arm swing (CMJas) at the 3 different time points. \# $p<0.05$ between periods, \#\# $\mathrm{p}<0.01$ between periods, ${ }^{* *} \mathrm{p}<0.01$ within period.

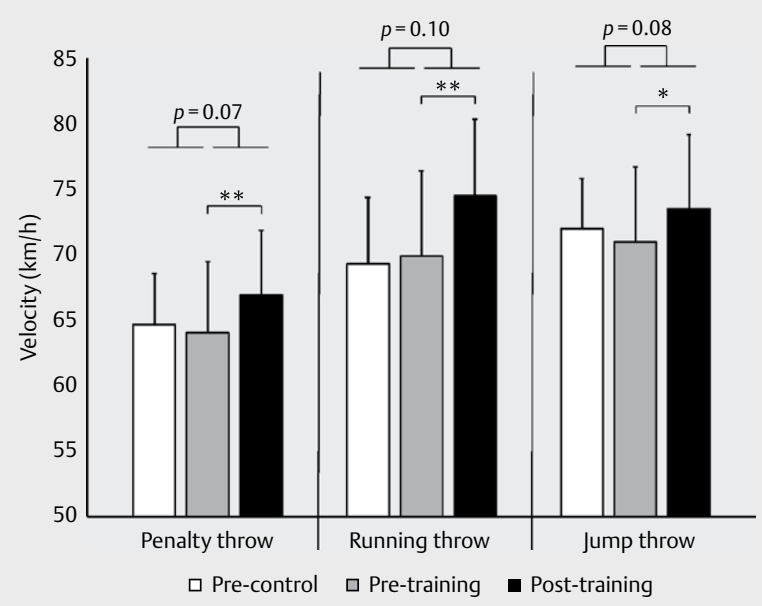

Fig. 4 Throwing velocity in the penalty throw, running throw and jump throw at 3 three different time points. ${ }^{*} p<0.05$ within period, ${ }^{* *} \mathrm{p}<0.01$ within period, $\mathrm{p}=0.05-0.10$ between periods have been indicated by the exact value.

resistance either by increasing the distance towards the wall bars or changing to a thicker band. The eccentric phase of each exercise was executed at a controlled tempo; however, it was emphasized that the concentric phase should be executed as explosively as possible. One minute rest was given between each set. The trainer of the team supervised all sessions, ensuring correct technique and execution.

The elastic resistance band was included in the teams' handball sessions and lasted 20-30 min and was conducted 3 times per week. It was conducted early in the session (control period: AugustOctober, training period: October-December) and replaced some of the warm-up and technical training that was performed in the control period, making the total, organized training time similar between the control and the training period. Also, the players were instructed not to adjust their individual training. The match frequency in the training period was the same as the control period, with one match per week.

\section{Statistical analysis}

Prior to the data analyses, we confirmed that the data was normally distributed with the Shapiro-Wilk test. Thus, paired t-tests were used to assess differences between and within the control and training periods. Statistical analyses were performed with SPSS version 24.0 (SPSS, Inc., Chicago, Illinois, USA). All results are presented as mean \pm SD and Cohen ` $s$ d effect size (ES). An effect size of 0.2 was considered small, 0.5 medium, and 0.8 large [6]. Statistical significance was accepted at $\mathrm{p} \leq 0.05$

\section{Results}

\section{Jump height}

There was a significant between-period difference in favor of the elastic resistance band training for both the CMJ (10 $\pm 9 \%$ vs. $-2 \pm 7 \%, p=0.02, E S=1.36,>$ Fig. 3 ) and the CMJas ( $10 \pm 8 \%$ vs. $-6 \pm 4 \%, p<0.01, E S=2.42$ ).

\section{Throwing velocity}

There were no statistically significant differences between the periods, although tendencies favoring the elastic resistance band program were observed for all 3 shots, ( $p=0.07-0.10$, > Fig. 4). Increased velocity for all 3 shots were observed within the elastic resistance band training period $(4-7 \%, \mathrm{p}<0.01-0.02$, ES $=0.44-0.74)$, whereas there were few changes in the control period.

\section{Squat}

For the explosive squat, there was a statistically significant between-period improvement for maximal power output and average velocity in favor of elastic resistance band training when performed with $20 \mathrm{~kg}$ (power: $10 \pm 10 \%$ vs. $-2 \pm 14 \%, p=0.04$, $E S=0.98$, Table 1; velocity: $11 \pm 7 \%$ vs. $-1 \pm 14 \%, p=0.02$, $E S=1.08$, Fig. $5 a$ ) and $30 \mathrm{~kg}$ (power: $12 \pm 8 \%$ vs. $0 \pm 14 \%, p=0.03$, $E S=1.02$; velocity: $10 \pm 7 \%$ vs. $0 \pm 12 \%, p=0.03$, $E S=1.03$ ), whereas at $40 \mathrm{~kg}, 50 \mathrm{~kg}$ and $60 \mathrm{~kg}$ the between-period changes were not statistically different $(p=0.11-0.49)$. There were increases from pre $_{\text {train }}$ to post $t_{\text {train }}$ in the power output and velocity for all loads (9-12\%; $p \leq 0.01, E S=0.44-0.95)$. The power outputs remained quite stable during the control period.

\section{Bench press}

For power output in the explosive bench press, there was a statistically significant between-period difference in favor of elastic resistance band training with the $15 \mathrm{~kg}$ load ( $12 \pm 14 \%$ vs. $1 \pm 10 \%$, $p=0.05$, ES $=0.90)$, but not for the remaining loads $(p=0.22-0.99)$. For average velocity, there was no significant difference between the 2 periods $(p=0.12-0.92$, $>$ Fig. $5 \mathbf{b})$. In the elastic resistance band period, power outputs and velocities were improved with all loads $(5-20 \%, p=0.01-0.04, E S=0.34-1.04)$, except for the velocity at $30 \mathrm{~kg}$, which only tended to be statistically different $(\mathrm{p}=$ 0.06 ). Power and velocity remained quite stable during the control period. 
- Table 1 Power output in the squat and bench press, and repeated agility run before and after the control and training period. Values are means \pm standard deviation.

\begin{tabular}{|c|c|c|c|}
\hline & Pre $_{\text {con }}$ & Pre $_{\text {train }}$ & Post $_{\text {train }}$ \\
\hline \multicolumn{4}{|l|}{ Squat test } \\
\hline $20 \mathrm{~kg}$ & $216 \pm 54 W$ & $212 \pm 30 W$ & $232 \pm 30 \mathrm{~W}^{\# * *}$ \\
\hline $30 \mathrm{~kg}$ & $277 \pm 52 W$ & $273 \pm 36 W$ & $305 \pm 40 \mathrm{~W} \# * * *^{*}$ \\
\hline $40 \mathrm{~kg}$ & $306 \pm 55 \mathrm{~W}$ & $322 \pm 43 \mathrm{~W}$ & $361 \pm 57 \mathrm{~W}^{* *}$ \\
\hline $50 \mathrm{~kg}$ & $326 \pm 71 \mathrm{~W}$ & $336 \pm 56 \mathrm{~W}$ & $376 \pm 73 \mathrm{~W}^{* *}$ \\
\hline $60 \mathrm{~kg}$ & $352 \pm 79 W$ & $352 \pm 78 \mathrm{~W}$ & $386 \pm 77 \mathrm{~W}^{* *}$ \\
\hline \multicolumn{4}{|c|}{ Bench press test } \\
\hline $15 \mathrm{~kg}$ & $167 \pm 24 W$ & $168 \pm 17 \mathrm{~W}$ & $187 \pm 25 \mathrm{~W}^{* *}$ \\
\hline $20 \mathrm{~kg}$ & $171 \pm 33 \mathrm{~W}$ & $173 \pm 19 W$ & $183 \pm 26 W^{*}$ \\
\hline $25 \mathrm{~kg}$ & $157 \pm 42 W$ & $156 \pm 34 \mathrm{~W}$ & $182 \pm 31 \mathrm{~W}^{* *}$ \\
\hline $30 \mathrm{~kg}$ & $137 \pm 42 W$ & $145 \pm 33 W$ & $155 \pm 28 \mathrm{~W}^{*}$ \\
\hline \multicolumn{4}{|c|}{ Repeated agility test } \\
\hline $\begin{array}{l}\text { Mean of } 6 \\
\text { runs }\end{array}$ & $29.0 \pm 1.0 \mathrm{~s}^{\# * *}$ & $28.3 \pm 0.9 \mathrm{~s}$ & $28.1 \pm 1.0 \mathrm{~s}$ \\
\hline Best run (s) & $27.9 \pm 0.9 \mathrm{~s}^{\# \#^{* *}}$ & $27.2 \pm 0.8 \mathrm{~s}$ & $27.6 \pm 1.0 \mathrm{~s}$ \\
\hline \multicolumn{4}{|c|}{ 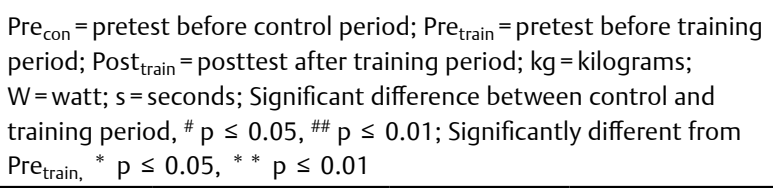 } \\
\hline
\end{tabular}

\section{Repeated agility run}

In the repeated agility test, the change during the control period was significantly different from the change in the training period for both the mean ( $-2 \pm 1 \%$ vs. $-1 \pm 1 \%, p=0.04$, ES = 1.36) and the fastest time $(-3 \pm 2 \%$ vs. $1 \pm 3 \%, p=0.01$, ES $=1.69)$. Within the control period, the time was reduced with $2 \%$ and $3 \%$ for the mean $(p<0.01, E S=0.73)$ and the fastest $(p<0.01, E S=0.84)$ time, respectively. Within the training period, no change for either the mean $(p=0.24)$ or the fastest $(p=0.11)$ time was observed.

\section{Discussion}

The main findings of the present study were that a brief, elastic resistance band program emphasizing explosive concentric contractions, performed 3 times per week as part of team handball practice, improved jump height, power output, and average velocity in the squat at low loads more than team handball training alone.

Power is defined as the product of force and velocity, and an increase in power could therefore be explained by an increase in force, velocity or both. Because the difference in the between-period changes appeared for jump height and low load but not higher load performance in the squat and bench press, the elastic resistance band program probably affected the velocity factor of the power output more than the force factor for the lower limbs. This speculation is supported by the velocity data, which showed an increased between-period difference in velocity in the squat. For the upper body, a similar overall picture emerged, although the results were less convincing because only the power output at the lowest weight tested in the bench press was different between the periods, and the improvements in throwing velocity for the 3 shot types only tend-
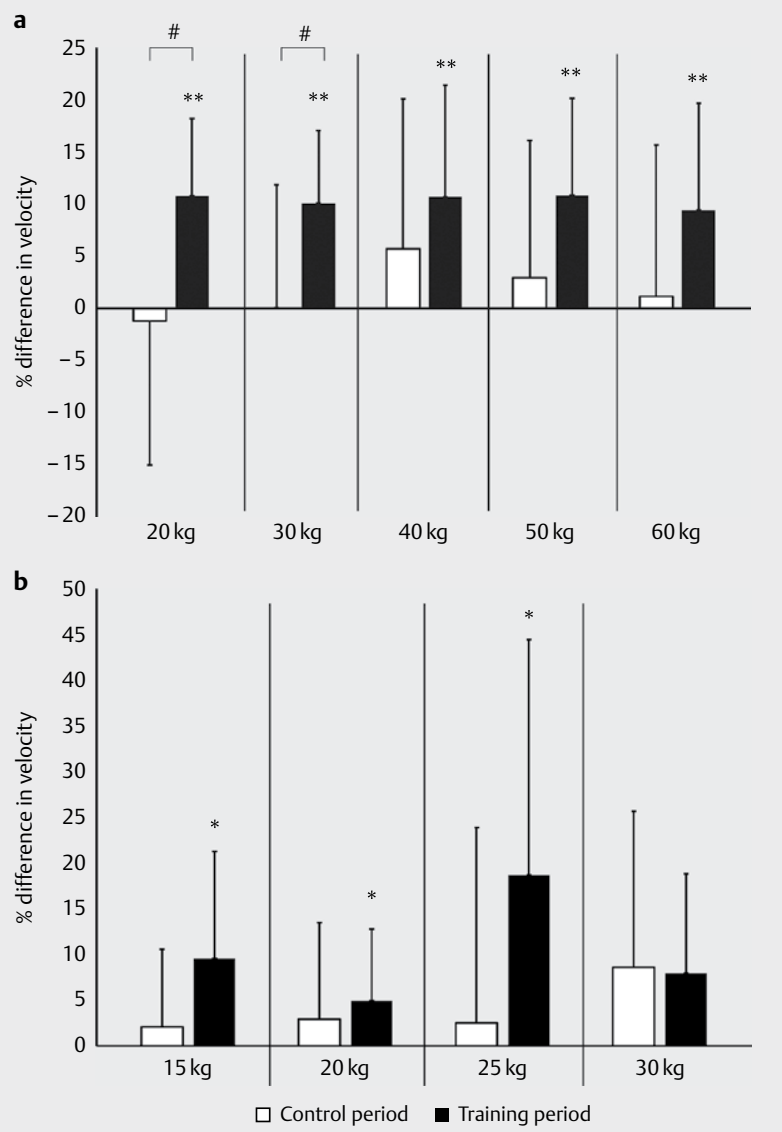

- Fig. 5 Percentage change in velocity for the different loads in the squat $(A)$ and the bench press $(B)$ during the control and training period. $\# p<0.05$ between periods, ${ }^{*} p<0.05$ within period, ${ }^{* *} \mathrm{p}<0.01$ within period.

ed to be statistically different between periods. Resistance training, particularly when performed explosively as in the current elastic resistance band program, has been shown to increase the ability to recruit motor-unit firing at high frequencies $[8,10]$, which can improve the rate of force development [7]. Further, resistance training leads to hypertrophy, especially of the type 2 fibers [2], which can further improve the production of power [7]. Other possible explanations could be increased tendon stiffness [16] or fascicle length [1].

The increased explosive ability for the lower extremities corresponds with Hermassi et al. [14], who examined the effects of 8 weeks resistance training among team handball players. They found a $12 \%$ increase in both CMJ and mean power output on a cycle ergometer after 8 weeks of strength training, compared to a control group that continued the usual training. However, another study did not find any increase in jumping performance after 6 weeks of resistance training [9]. Importantly, participants were not instructed to perform the exercises explosively [9].

Several studies investigating the effect of resistance training on throwing velocity have reported improved performance $[9,12,14,18,19,22]$. However, only one specified that the train- 
ing led to greater improvement than the control group [12], thus most studies are vulnerable to bias. Our observations of tendencies towards greater improvement for 3 different throws and power output in the bench press with light loads for elastic resistance band training and compared to regular handball training provide additional support for the notion that explosive resistance training is beneficial for throwing performance.

To our knowledge, only 2 studies have examined the effect of resistance training on agility performance $[15,25]$. Both studies showed an improvement in modified t-tests after 6 and 10 weeks of resistance training. The discrepant findings from the present study could be explained by the test procedures and interventions. First, the agility courses were shorter in those studies. The course used by Hermassi et al. [15] was completed in 6 to $7 \mathrm{~s}$, and the participants in both studies ran the course only once. Therefore, it is likely that power and strength were of greater importance in those courses than the one used in our study. Second, the training program in both studies consisted of more exercises targeting the leg and hip extensors, and both interventions included sprint exercises with some of them emphasizing change of direction, which would increase the specificity towards the agility course. Due to greater training volume and more specific exercises in Hermassi et al. [15] and van den Tillaar et al. [25], it seems plausible that the adaptations from those programs were more transferable to the agility test than in our study.

The primary limitations of the present study were the small sample size and lack of a randomized control group. To partly compensate for this, we included a control period prior to the elastic resistance band intervention, and to be considered a real change, the improvements in the intervention had to be greater than the improvements in the control period. Furthermore, when participants act as their own controls, statistical power is also improved. Nevertheless, the weakness of this design was illustrated by the improvement in the shuttle run test during the control period, which was significantly greater than during the intervention period, perhaps due to a learning effect. To keep the motivation similar in all tests, the participants were blinded to the results until the end of the study. Finally, only young female players with little experience with resistance training were recruited, therefore the findings from the present study cannot necessarily be generalized to other populations of players.

In conclusion, a brief, explosive, full-body elastic resistance band program, incorporated into the regular handball training sessions for 9 weeks, improved explosive lower-limb performance in young female handball players more than handball training alone. Therefore, it could be useful and feasible to implement elastic resistance band training as part of handball teams ` regular training sessions, particularly when there is limited time and conventional resistance training equipment available.

\section{Conflict of Interest}

No conflict of interest has been declared by the authors.

\section{References}

[1] Alegre LM, Jimenez F, Gonzalo-Orden JM, Martin-Acero R, Aguado X. Effects of dynamic resistance training on fascicle length and isometric strength. J Sports Sci 2006; 24: 501-508

[2] Andersen JL, Aagaard P. Effects of strength training on muscle fiber types and size; consequences for athletes training for high-intensity sport. Scand J Med Sci Sports 2010; 20: (Suppl 2): 32-38

[3] Bayios IA, Anastasopoulou EM, Sioudris DS, Boudolos KD. Relationship between isokinetic strength of the internal and external shoulder rotators and ball velocity in team handball. J Sports Med Phys Fitness 2001; 41: 229-235

[4] Chelly MS, Hermassi S, Aouadi R, Khalifa R, Van den Tillaar R, Chamari K, Shephard RJ. Match analysis of elite adolescent team handball players. J Strength Cond Res 2011; 25: 2410-2417

[5] Chelly MS, Hermassi S, Shephard RJ. Relationships between power and strength of the upper and lower limb muscles and throwing velocity in male handball players. J Strength Cond Res 2010; 24: 1480-1487

[6] Cohen J. Statistical Power Analysis for the Behavioral Sciences. 2nd ed. Hillsdale, N.J: L. Erlbaum Associates; 1988

[7] Cormie P, McGuigan MR, Newton RU. Developing maximal neuromuscular power: Part 1--biological basis of maximal power production. Sports Med 2011; 41: 17-38

[8] Folland JP, Williams AG. The adaptations to strength training : Morphological and neurological contributions to increased strength. Sports Med 2007; 37: 145-168

[9] Gorostiaga EM, Izquierdo M, Iturralde P, Ruesta M, Ibanez J. Effects of heavy resistance training on maximal and explosive force production, endurance and serum hormones in adolescent handball players. Eur ] Appl Physiol Occup Physiol 1999; 80: 485-493

[10] Griffin L, Cafarelli E. Resistance training: Cortical, spinal, and motor unit adaptations. Can J Appl Physiol 2005; 30: 328-340

[11] Harriss DJ, Macsween A, Atkinson G. Standards for ethics in sport and exercise science research: 2018 update. Int J Sports Med 2017; 38: 1126-1131

[12] Hermassi S, Chelly MS, Fathloun M, Shephard RJ. The effect of heavyvs. moderate-load training on the development of strength, power, and throwing ball velocity in male handball players. J Strength Cond Res 2010; 24: 2408-2418

[13] Hermassi S, Chelly MS, Fieseler G, Bartels T, Schulze S, Delank KS, Shephard RJ, Schwesig R. Effects of in-season explosive strength training on maximal leg strength, jumping, sprinting, and intermittent aerobic performance in male handball athletes. Sportverletz Sportschaden 2017; 31: 167-173

[14] Hermassi S, Chelly MS, Tabka Z, Shephard RJ, Chamari K. Effects of 8 -week in-season upper and lower limb heavy resistance training on the peak power, throwing velocity, and sprint performance of elite male handball players. J Strength Cond Res 2011; 25: 2424-2433

[15] Hermassi S, Wollny R, Schwesig R, Shephard RJ, Chelly MS. Effects of in-season circuit training on physical abilities in male handball players. J Strength Cond Res 2017, doi:10.1519/JSC.0000000000002270

[16] Kubo K, Morimoto M, Komuro T, Yata H, Tsunoda N, Kanehisa H, Fukunaga T. Effects of plyometric and weight training on muscletendon complex and jump performance. Med Sci Sports Exerc 2007; 39: $1801-1810$

[17] Marques MC, Gonzalez-Badillo JJ. In-season resistance training and detraining in professional team handball players. J Strength Cond Res 2006; 20: 563-571

[18] Mascarin NC, de Lira CAB, Vancini RL, da Silva AC, Andrade MS. The effects of preventive rubber band training on shoulder joint imbalance and throwing performance in handball players: A randomized and prospective study. J Bodyw Mov Ther 2017; 21: 1017-1023 
[19] Mascarin NC, de Lira CAB, Vancini RL, de Castro Pochini A, da Silva AC, Dos Santos Andrade M. Strength training using elastic bands: Improvement of muscle power and throwing performance in young female handball players. J Sport Rehabil 2017; 26: 245-252

[20] Ortega-Becerra M, Pareja-Blanco F, Jimenez-Reyes P, Cuadrado-Penafiel V, Gonzalez-Badillo JJ. Determinant factors of physical performance and specific throwing in handball players of different ages. J Strength Cond Res 2017, doi:10.1519/JSC.0000000000002050

[21] Povoas SC, Seabra AF, Ascensao AA, Magalhaes J, Soares JM, Rebelo AN. Physical and physiological demands of elite team handball. J Strength Cond Res 2012; 26: 3365-3375

[22] Sabido R, Hernandez-Davo JL, Botella J, Moya M. Effects of 4-week training intervention with unknown loads on power output performance and throwing velocity in junior team handball players. PLoS One 2016; 11: e0157648
[23] Saeterbakken AH, van den Tillaar R, Seiler S. Effect of core stability training on throwing velocity in female handball players. J Strength Cond Res 2011; 25: 712-718

[24] Soria-Gila MA, Chirosa IJ, Bautista IJ, Baena S, Chirosa LJ. Effects of variable resistance training on maximal strength: a meta-analysis. J Strength Cond Res 2015; 29: 3260-3270

[25] Van den Tillaar R, Waade L, Roaas T. Comparison of the effects of 6 weeks of squat training with a plyometric training programme upon different physical tests in adolescent team handball players. Acta Kinesiologiae Universitatis Tartuensis 2015; 21: 75-88

[26] Wik EH, Luteberget LS, Spencer M. Activity profiles in international women's team handball using PlayerLoad. Int J Sports Physiol Perform 2017; 12: 934-942 